\title{
PREDICAMENT OF KNOWLEDGE SOCIETY: AN INQUIRY
}

\author{
Gurudutta P. Japee \\ University School of Commerce, Gujarat University, India \\ <profgurudutta1@gmail.com>
}

\begin{abstract}
This study sets out to establish conceptual demarcations, more concordant to the theoretical acquisition with regard to the knowledge society. The knowledge society is a form of society in which members are examining ideas constantly. In Knowledge society there ought to be communicative rationality, wherein, arguments and receptive audience are very important. The communicative phenomena in the knowledge society, knowledge should be participatory. This will occur only when society is knowledgeable and should have potency to think, participate and respond critically.

This type of knowledge domain will go beyond information because mere information is not knowledge, it requires Understanding and perception, imaginative framework, communicative and creative framework than only knowledge society would function and humanities (Human approach- when men is at the centre of inquiry and inquiry must be human centric) must be its hard core. Society having equalitarian justice, question of empowerment will not arise; this will create equal potency of freedom and capacity to respond. and can have healthy communication. It would be a dialoguing society, where in negotiation will never seize.

Society without Motivational crisis, Rationality crisis and Legitimacy crisis can become knowledge society provided they have a sharable life world, which would respect alternative way of thinking and it would be communicative.

Virtues like empathy, compassion etc must be at the centre of knowledge society. There should be absence of dark emotions (sadness, suffering, anxiety, envy, boredom, loneliness, guilt, anger) in knowledge society. Moreover, this entire phenomenon is not possible without nudging by the authority keeping libertarian paternalism and choice architecture.
\end{abstract}

Keywords: Audience, Communicative Framework, Nudging, Libertarian Paternalism and Choice Architecture

\section{Introduction}

This study sets out to establish conceptual demarcations, more concordant to the theoretical acquisition about the knowledge society. In the knowledge society, there ought to be 
a systematic search of knowledge, and it ought to be communicable. Arguments and receptive audience are essential. The rationally communicative phenomena in the social demand to be participatory wherein, knowledge is open to negotiations. It is a society wherein negotiation will never be suspended by any power play. Its basic presupposition is that it would be a knowledge-seeking society, and must have the potency to think and negotiate. The participatory mind is the prerequisite of the knowledge society. The primary pursuit of the society is to be inquisitive to learn. Knowledge will transmigrate information and can become a pathway to creativity. Knowledge society as such is not only a learning society but a creative society which possesses imaginative understanding as its underpinning.

\section{Culture of learning society- An ardent need}

This study sets out to establish conceptual demarcations, more concordant to the theoretical acquisition about the knowledge society. In the knowledge society, there ought to be a systematic search of knowledge, and it ought to be communicable. The question here is how to create a learning society?

It is an imagined community like nationalism, which nurtured through learning. It ensures learning as a qualitative value and has to create a learning space in Society. All the stakeholders - Society, State, Administration, Institutions, Teachers, and Students should have a learning space.

1. They should be treated as a learning agent.

2. They should create a broad mindset.

3. They should accept plurality or diversity

4. They should treat inclusiveness as a path of learning.

5. They should treat academics beyond the pigeon hole.

6. The hardcore of learning Society should be interdisciplinarity.

The figure 1. represent stakeholders of the knowledge society and their functioning.

This will bring a paradigm shift in the knowledge system. Students, teachers, institutions would become the agent of the shift. There is an ardent need to shift rut learning and ensure creative and critical learning. "Critical" here in the Kantian Sense a self-reflective examination of the limits and validity of knowledge. All the agents though different yet they survive through family resemblance. The thread of equity of pursuit in learning makes them one family. All are working as the agent of learning society, and they operate within a shared cultural space of learning. State and society work as a nudging agent for learning society. According to Richard Thaler and Cass Sunstein Nudge means 

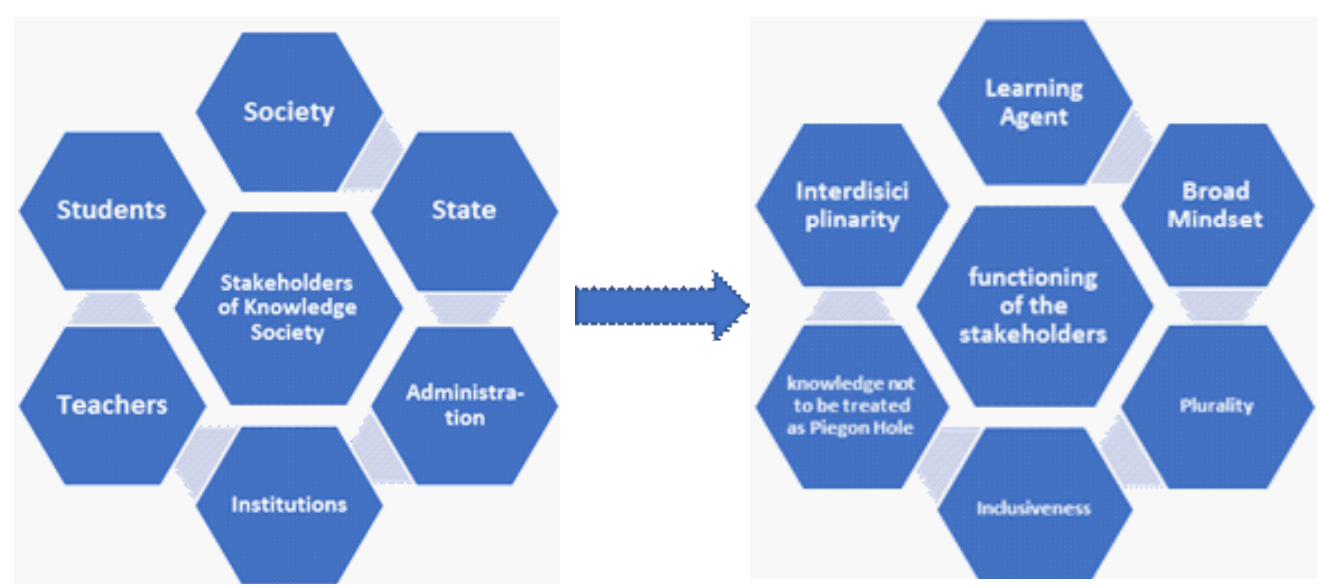

Figure 1. represent stakeholders of the knowledge society and their functioning

any aspect of choice architecture that changes people's behavior predictably, and is cheap and easy to avoid. Where nudging is not possible, then it is a stubborn and vacuous state. It would exercise, not even a rut learning but also imitation learning. Education only structured learning will undoubtedly create a non-learning passive society.

In Learning society, the legitimation of learning is possible only when a debate prescribed, procured, and pursued. Learning society has no uncontroversial defining essence. Here dissent is a value and not a distortion of spirit. Not abiding is the abiding agenda of learning society. Difference and dichotomies are to respect in creating a learning society. Differences are not disjunctions, and they are not to treat as guilt but a grammar of learning society. Learning society can take place only when debates, reflections, and discourses are never suspended nor shutter down by the state or society.

The logic of learning society is to expand the horizon of knowledge and to be enlightened through knowledge. Sir Karl Popper has rightly said ignorance is infinite, whereas knowledge is limited. Quest for learning society has not to shower in the infinite notion of ignorance, but to emancipate from the ocean of ignorance. Learning society should be a collective upsurge of knowledge.

To ask for the learning society is not to presume that the past society was an unlearning society, because learning is a perennial quest of the human mind ever old and ever new. Learning is a civilizing activity, and Knowledge is both transmitting and transforming phenomenon. Knowledge is an engaging activity. Learning society is not widgets of the passing scene; it is useful, productive, and valuable. 


\section{Argumentative Rationality through Communication}

We use the term argumentation for that type of speech in which participants thematize, contest, validate claims and attempt, either to substantiate and criticize through arguments. An argument contains reasons or grounds that connected logically with the validity claims. The 'strength' of an argument is measured in a given context by the soundness of the seen reasons. In an argumentative discourse, one should be either able to convince or capable of negotiating with the participant.

The first part of the paper is the discourse on a Knowledge Society, in which a community of enquirers operates within modes of argumentation. The writing and evaluation of arguments should become a natural part of the Knowledge Society.

To make the strongest possible case for the knowledge society, the first thing to do is nurturing Peoples' Potentiality \& Capacity to think. To do so, Argumentation should be positively imbibed \& insulated as a practice of society.

We acquire theoretical knowledge and moral insight, extend and review our evaluative language, and overcome self-deception and difficulties in argumentation'. The potential of developing the capacity of critical argumentation is the production of scholars and citizens. In the contemporary world, knowledge society has to raise and solve the problems.

Argumentation is an activity for the persuasion of once argument and can lead to dialogue and can lead to shareability. Making a sharable argument is central to communicative action: where there is a possibility of influencing the public political sphere, citizens' capacity to make arguments and to accept 'the persuasive force of the better argument' which provides grounds for hoping right and just decisions.

According to Habermas, we should try to make a University (and modern democratic society), in a vision of communication, should be free from the constraints of power relations. Universities and modern democratic societies are connected by a shared necessity for the processes of critical argumentation to ensure their health. Therefore, from this perspective, it is not far-fetched to propose that knowledge society is the acme of the human capacity to 'raise claims to validity that we are prepared to defend against criticism' as a form of participation in the direction society takes. (Habermas 1990:56).

Communicative Rationality is operative only when there is a sharable life world, molding of virtues are essential. Present-day world molded in an institutionalized structure, according to Habermas Institutional crisis suffers from a crisis of Rationality, Motivation, and legitimation. The 
discourse of modernity becomes noncommunicative. However, ideals of modernity are still helpful to make humanities progressive. Still, it is useful for human emancipation. Such ideals are not to be thrown away by sciences, humanities, or even societies. Knowledge society should be constructed in accord with this ideal. Education must nurture value or core of wisdom, which helps to flourish knowledge society.

\section{Quest of Knowledge Society}

The concept of knowledge society starts with enlightenment. The pursuit of enlightenment is to understand man and nature through reason.

The first question here is how to understand the Reason, and it is a neutral quest of knowledge through Reason. It is Prejudice free rational inquiry and which can be earned through prejudice-free knowledge. However, what about the understanding of man. Man is not only a rational animal because there can not be a universal claim of rationality. Two modes of thoughts emerge. The first is through Reason one can understand, and one can make a universal claim, through a rational method of inquiry, the other is to Treat Reason as only a faculty of analyzing, organizing and critical evaluation.

Reason gives us certainty, but it also gives uncertainty, because every argument can be encountered. Natural science, through scientific inquiry, can make a Universal claim. However, thinkers like Kuhn, Popper, Lakatos, Feyerabend have rejected the Universal claim of science. To treat Scientific thinking only as inductive thinking, or inductive methodology to create valid knowledge claim, that Backnian enthusiasm was questioned. This was a nodal point for the change even in human sciences. Rationality is not to be treated as the hallmark of Man and which can be studied and evaluated through the yardstick of reason alone. William Barret wrote a book on existentialism; its title is "Irrationality of a Men." Man is not only a rational being and cannot be controlled or understood alone by reason or by rational structures. Reason gives a certainty, that claim is questioned.

According to Kuhn, " Science is a social product and is the product of conventions about what makes truth."

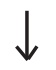

According to Popper, "Progress can be achieved even without truth-knowledge accumaltes and gives us a better understanding of the real empirical world."

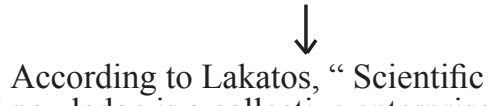

knowledge is a collective enterprise. Scientific theories are produced and make sense within organised communities and bodies of theory."<smiles>C1CCCC1</smiles>

According to Feyerabend, "Science should promote the freedom of the individual." Feyerabend's position is that of Popper taken to its logical conclusion. 
Humanity and Social Sciences based on positivist methodology were challenged, it gave way to a new mode of human sciences because, in human sciences, the man in its totality is the center of inquiry. Man's seeing, perceiving, understanding and interpreting, constructing, and deconstructing became the center of inquiry. Human sciences entered into many dimensions like anthropology, History, Language, Sociology, Phenomenology, and History of Emotions. Culture became the core of the study of human sciences, along with language and discourse. The study of culture deals with how culture is constructed, what are its presumptions and practices. How they mold, motivate, and express human experience, how culture changes, mold, and translate everyday life. How culture is to be understood and interpreted; these are the questions cultural study tries to inquire. Knowledge is a secularising process, and it asserts a secular knowledge

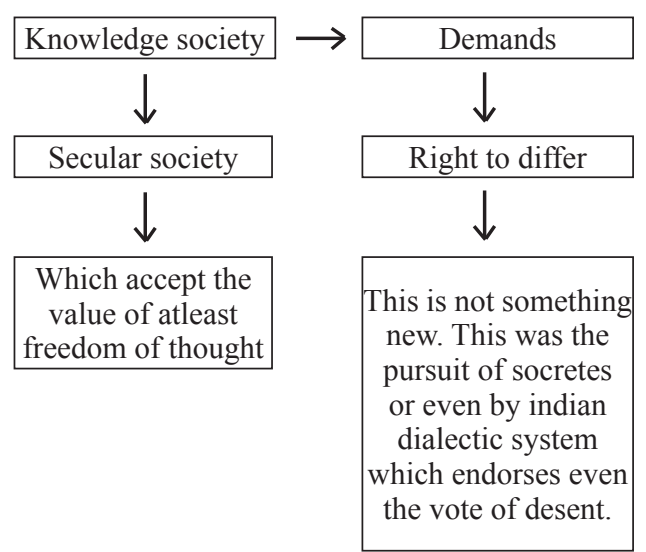

claim. Such knowledge claim must have secular, undogmatic, free \& fair, not even governed by the dogma of progress and development. The dogma of progress and development alone is either a myth or prejudice.

Critical discourses are the network of the knowledge society. The knowledge society is not enslaving society, but it demands the spirit of freedom and enlightenment.

\section{What is Knowledge society?}

It is not a utopian construction, wherein knowledge is nonnegotiable i.e., to say - Growth of knowledge, possibilities of growth of Communication and social change is not possible. A primary concern of knowledge society is for social change (change is for betterment). The basic thesis of a knowledge society is for the betterment of society and must have a communicative model. It means, it should be non-hierarchical equalitarian society, wherein knowledge and ignorance both are sharable/communicable. It is not only argumentative or debating society but experiments also, because they do understand the difference between knowledge and rhetoric and the anxiety of knowledge society is inquisitiveness to know and considers not only as reproduction. In this sense, reproduction is only a myth.

Knowledge society, at its core ideas and critical thinking, and it operates through fair negotiation- a tolerant 
negotiation. Empowerment is the crucial test of the knowledge society because it accepts non-hierarichal growth of knowledge.

The Foucauldian study was an archeological inquiry of human society. How society is constructed and how through practices of institutions, human subjectivity has been objectified or made an object. The archeology of institutions like asylum, prison house, medicine, knowledge, and power has been studied. His archaeological study of the institution treats society as a social construct, and it creates power. The individual subject becomes subjugated through social practices which creates a macro and micropower. Macro power is visible while micropower being suttle is unseen but is more potent than macro-level power. Knowledge as a social institution is a power game. In society, to coin an individual identity as literate or illiterate creates not only different, but it also creates a hierarchical power structure. In this respect to Foucault, knowledge is a powerful construction.

How to secularise knowledge is a perennial question, which the Presentday society inquires. How to construct a knowledge society? A learning society which makes knowledge a free quest of mind and not a monopolized rut education. In the quest of a knowledge society, administration and state can play a nudging role.

Nudging is essential, and Nudging is an inquiry to change peoples' behavior predictably. For that libertarian paternalism is needed, that is to say, to encourage people to act in their own best interest without restricting their freedom of choice. To change the choice architecture, particular public behavior is to be encouraged, and this encouragement is called nudge. It is a kind of persuasion by the authority for the betterment of the choice architect, and it should be peoples' choice not governed or detected by the government. At the heart of the nudge, it is libertarian exercise which assure freedom to choose and act accordingly. How this liberal attempt can be translated and transformed is a question needs an answer. The answer is by creating a learning society which is the demand of the day.

How to create a learning society? It ought to be a collective effort by learning institutions and society, even individuals. This is to be seen as a cultural cognitive shift, necessary for the betterment of individual and society, but it is to be treated as a nonsingular shift which is cognized in the experience of individual, society, and culture. This is a kind of individual and collective persuasion and execution as a way of cultural expression.

Knowledge society can sustain and can function not in a moral void, and it should be free from the dark emotions (sadness, suffering, anxiety, envy, boredom, loneliness, guilt, anger), so 


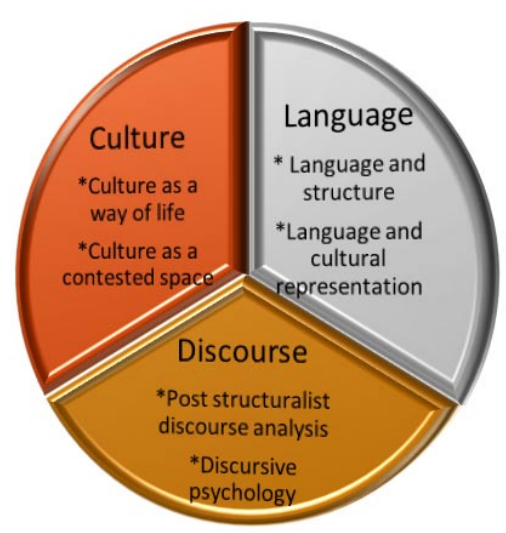

that tolerant qualitative discourse will become it is a real and valid expression. It should not be a mere formal idea, myth or metaphor but living and upsurging reality. It is a creation and also acculturation of individuals and society, which can be the predicament of a knowledge society. Let us be a predicant of learning society. []

\section{References}

Foucault M. (2014) Lectures on will to know, originally published in Great Britain by Macmillan Publishers.

Habermas J. (1971) Towards a Rational Society. Heinemann publishers, London.

Habermas J. (1984) The Theory of Communicative Action, Volume One: Reason and the Rationalisation of Society. Trans. T. McCarthy. Boston, MA: Beacon Press.

Habermas J. (1987) The Theory of Communicative Action, Volume Two: Lifeworld and system: A Critique Functionalist Reason. Trans. T. McCarthy. Boston, MA: Beacon Press.

Habermas J. (1989) the idea of the University: Learning Processes. In J. Habermas. The New Conservatism Cultural criticism and the Historians' Debate, Trans. S. Weber Nicholson. Cambridge: Polity Press.

Habermas J. (1990) Moral Consciousness and Communicative Action. Trans. C. Lenhardt and S. Nicholsen. Cambridge: Polity Press in association with Basil Blackwell.

Stiglitz J \& Greenwald B (2015), Creating a Learning Society, A new approach to growth, development and social change, Columbia university press, New York.

Smith M (1998) Social Science in question, sage publications limited, London, Pg. no 218.

Smith M (1998) Social Science in question, Language Culture and discourse, sage publications limited, London, Pg. no 233.

Thaler R \& Sunstein C (2017) Nudge, Improving decision about health, wealth and happiness, Macat International, London. 